\title{
Effects of Self-Selected Exercise on Strength in Charcot-Marie-Tooth Disease Subtypes
}

\author{
Djurdja Djordjevic, Sabrina Fell, Steven Baker
}

\begin{abstract}
Background: Preliminary studies have supported the utility of exercise as a treatment for Charcot-Marie-Tooth disease (CMT) patients. Despite being the most common inherited neuropathy, there remains a paucity of guidelines for CMT management. Methods: A retrospective chart review was performed on 297 CMT patients. Self-reported exercise and strength results from standardized dynamometer testing were obtained from adult patients' first visits. Values were converted and analyzed based on previously reported age- and sex-matched normative values. Results: Participants with CMT2 had greater strength values than those with CMT1 in hand grip, elbow flexion, and dorsiflexion $(p<0.05)$. Participants with CMT1 and CMT2 who exercised were statistically significantly stronger in elbow flexion and dorsiflexion than those who did not exercise. Conclusions: These preliminary results suggest that self-directed exercise is associated with greater strength in CMT patients of both CMT1 and CMT2 subtypes. Self-directed exercise may be a convenient, sustainable, and effective method of improving strength and decreasing disability in this population. Future research should explore the type of exercise prescription that best addresses the needs of the CMT population.
\end{abstract}

RÉSUMÉ: Effets sur la force d'exercices choisis par le patient dans différents sous-types de la maladie de Charcot-Marie-Tooth. Contexte: Des études préliminaires ont attesté l'utilité de l'exercice comme traitement des patients atteints de la maladie de Charcot-Marie-Tooth (CMT). Bien que cette maladie soit la neuropathie héréditaire la plus fréquente, il existe peu de lignes directrices quant à son traitement. Méthodologie: Nous avons effectué une revue rétrospective des dossiers de 297 patients atteints de CMT. Nous avons relevé l'information rapportée par les patients adultes lors de leur première visite concernant l'exercice et les résultats d'épreuves de force standardisées au dynamomètre. Les valeurs ont été converties et analysées selon les valeurs normatives rapportées antérieurement, appariées pour l'âge et le sexe. Résultats: Les participants atteints de CMT2 avaient des valeurs de force supérieures à celles des patients atteints de CMT1 aux tests de préhension manuelle, de flexion du coude et de dorsiflexion (p < 0.05). La force à la flexion du coude et à la dorsiflexion était significativement plus élevée chez les patients atteints de CMT1 et de CMT2 qui faisaient de l'exercice par rapport à ceux qui n'en faisaient pas. Conclusions: Selon ces résultats préliminaires, l'exercice autogéré est associé à une plus grande force physique chez les patients atteints de CMT, que ce soit CMT1 ou CMT2. L'exercice choisi par le sujet peut être une option pratique, durable et efficace d'améliorer la force et de diminuer l'invalidité dans cette population. De nouvelles études devraient explorer le type d'exercice qui satisfait le mieux les besoins des patients atteints de CMT.

Keywords: neurology - adult, neurology - general, neuromuscular disorders, neuropathy, polyneuropathy

doi:10.1017/cjn.2017.204

Can J Neurol Sci. 2017; 44: 572-576

\section{INTRODUCTION}

Charcot-Marie-Tooth (CMT) is the most common polygenic peripheral nerve disease, defined by axonal, dysmyelinating, and intermediate phenotypes. ${ }^{1}$ CMT results in progressive distal muscle weakness, loss of sensation, and deep tendon reflexes, ${ }^{2}$ as well as such consequent distal deformities as pes cavus and equinus. ${ }^{3}$ The associated weakness and restricted movement results in muscle cramps, ${ }^{3}$ imbalance, and gait difficulties. ${ }^{4}$

The estimated incidence of CMT has been recently increased from 1:2,500 to as high as $\sim 1: 1,200 .^{5}$ Despite such a high prevalence, there remains a paucity of published studies to inform guidelines for CMT management. Current treatments include such nonsurgical interventions as stretching, bracing, and serial casting, although there is conflicting evidence regarding the long-term efficacy and sustainability of these methods. ${ }^{6}$ Previous studies have supported the utility of rehabilitation as a treatment for CMT patients. ${ }^{7}$ In particular, a small body of evidence suggests that exercise may be beneficial for long-term strength and functioning in CMT (see Kilmer [2002] ${ }^{8}$ and Sman et al. [2015] ${ }^{9}$ for reviews). In addition, preliminary research has shown that at-home resistance training can result in improvements in both strength and strength endurance. ${ }^{10}$ However, the literature supporting the use of exercise as a treatment for CMT is still limited. Our study aimed to examine differences in strength among exercising and nonexercising individuals from both the CMT1 and CMT2 subtypes.

From the Department of Medicine, McMaster University, Hamilton, Ontario, Canada (DD, SB); Department of Human Health and Nutritional Sciences, University of Guelph, Guelph, Ontario, Canada (SF); Department of Medicine, Neuromuscular Disease Clinic, McMaster University Medical Centre, Hamilton, Ontario, Canada (SB).

Received November 10, 2016. Final Revisions Submitted March 18, 2017. Date of ACCEPTANCE APRiL 2, 2017.

Correspondence to: Steven Baker, Department of Medicine, Neuromuscular Disease

Clinic, HSC 2H22, McMaster University, Hamilton, Ontario, L8N 3Z5, Canada.

E-mail: bakersk@mcmaster.ca 


\section{METHODS}

The charts of 297 CMT patients at McMaster University Medical Centre in Hamilton, Ontario, were reviewed retrospectively. The diagnosis of CMT was established in these patients in one of two ways: (1) positive genetic testing or (2) positive family history (with genetic testing) along with supportive clinical exam and electrophysiology (i.e., terminal motor latency $>150 \%$ upper limit of normal; median motor conduction velocity $<35 \mathrm{~m} / \mathrm{s}$ ), via either genetic testing, or family history and electrophysiological studies, in keeping with a hereditary dysmyelinating axonopathy in the setting of appropriate clinical dysmorphisms.

Data were collected from all visits and included demographic information, self-reported exercise patterns, and strength testing as recorded in the charts. Strength testing was achieved by standard objective measurement using Biodex (Biodex Medical Systems, Shirley, New York) and Jamar dynamometers (Performance Health, Warrenville, Illinois), according to a standardized procedure. ${ }^{11}$ Hand grip was measured in kilograms ( $\mathrm{kg})$, and muscle strength in other groups was measured at highest peak torque (newton-meters, $\mathrm{Nm}$ ). Since many patients were lost to follow-up, the earliest visit with each patient was used for data analysis. Isometric strength testing scores were recorded for right- and left-hand grip strength, knee extension, elbow flexion, and ankle dorsiflexion. Strength values were converted according to age- and sex-matched normative values, by adjusting participants' scores based on previously reported differences from baseline. ${ }^{12}$ Hand grip strength was converted for each participant into a percentage of normal, based on previously reported age- and sex-normative values. ${ }^{13,14}$

The data were analyzed quantitatively via $t$ test in SPSS with a significance value of $p<0.05$. Participants who did not have a known CMT subtype diagnosis (CMT1 or CMT2) or who did not have sufficient strength data recorded were excluded from the analyses (a total of 112 patients excluded). Pediatric patients (under 18 years of age) were also excluded due to a lack of available normative values. For analysis of CMT1 subtypes, only those participants who had a known genetically diagnosed subtype of CMT1A, CMT1B, or CMT1D were included. In total, 117 CMT1 patients and 128 CMT2 patients were compared. Of these participants, $11 \mathrm{CMT} 1$ and $16 \mathrm{CMT} 2$ patients did exercise and were included in the exercise-positive (EP) group, while 8 CMT1 and 12 CMT2 patients did not exercise and were included in the exercisenegative (EN) group (Table 1). The remaining participants either did not have any exercise patterns recorded in their charts or had exercise that did not meet the inclusion or exclusion criteria.

A number of inclusion and exclusion criteria were employed for comparison of participants who exercised versus those who did not in order to optimize the validity of our results. The inclusion criteria for the EP group included the following: (1) those who reported their exercise routine frequency either as two or more times per week or as two or more types of exercises that met the criteria; (2) in order to meet the criteria, exercise types must have been whole-body training for strength building or cardiovascular exercise (e.g., walking, weights, aquafit). The exclusion criteria for this group were as follows: (1) those who did not indicate whether or not they did exercise; (2) those who only indicated that they did exercise but did not specify the frequency or type of exercise; and (3) those who did not do whole-body training but rather performed targeted exercise (e.g., physiotherapy for knee only).

In the EN group, only those who specifically indicated that they did not exercise were included. The exclusion criteria for this group were as follows: (1) those who did not indicate whether or not they did any exercise; and (2) those who specified a limitation that made it unclear for how long ago they stopped exercising (e.g., stopped due to a cardiac problem). In addition, some participants did not have data recorded for one or more measures, in which case they were only included for the measures that were recorded.

\section{RESUlts}

Identical analyses were performed using both the scores adjusted for age and sex differences and the original strength values. Conversion of scores did not alter the statistical significance of our results. Of the charts reviewed, 117 adult participants had CMT1 or a genetically confirmed subtype of CMT1, and 125 had CMT2 or a genetically confirmed subtype of CMT2. Power testing demonstrated that CMT2 participants were stronger than CMT1 participants in right- and left-hand grip, dorsiflexion, and elbow flexion (Figure 1). Knee extension did not reach statistical significance $(p=0.1259)$. CMT1 was further examined based on its subtypes, CMT1A versus CMT1B and CMT1D. CMT1A was weaker $(p<0.05)$ than CMT1B and 1D in knee extension, with other strength values not reaching statistical significance (Figure 2). Unfortunately, the sample size was too small to examine CMT1B and D individually, so that these participants were combined.

When comparing the data of the participants included in the exercise analysis, the group of 27 participants in the EP group were stronger than the 20 participants in the EN group in elbow flexion and dorsiflexion $(p<0.05)$ (Figure 3). Exercise did not have an impact on hand grip strength.

The CMT1 and CMT2 groups were further analyzed based on their exercise patterns. Within CMT1 participants, dorsiflexion remained statistically significantly higher in the EP group compared to those in the EN group $(p<0.05)$ (Figure 4). When comparing only those with CMT2 who did exercise versus those who did not,

Table 1: Age and sex information for each group analyzed

\begin{tabular}{|c|c|c|c|c|c|c|c|c|c|c|}
\hline & CMT1 & CMT2 & $\begin{array}{c}\text { Yes } \\
\text { Exercise }\end{array}$ & $\begin{array}{c}\text { No } \\
\text { Exercise }\end{array}$ & $\begin{array}{c}\text { Yes } \\
\text { exercise: } \\
\text { CMT1 }\end{array}$ & $\begin{array}{c}\text { No } \\
\text { Exercise: } \\
\text { CMT1 }\end{array}$ & $\begin{array}{c}\text { Yes } \\
\text { exercise: } \\
\text { CMT2 }\end{array}$ & $\begin{array}{c}\text { No } \\
\text { Exercise: } \\
\text { CMT2 }\end{array}$ & CMT1A & CMT1 B/D \\
\hline Total number & $\begin{array}{l}117 \text { ( } 28 \text { children } \\
\text { excluded })\end{array}$ & $\begin{array}{l}128 \text { ( } 12 \text { children } \\
\text { excluded })\end{array}$ & 27 & 20 & 11 & 8 & 16 & 12 & 91 & 12 \\
\hline Avg age & 42.3 & 55.77 & 51.07 & 48.05 & 41 & 38.125 & 58 & 54.667 & 42.978 & 42.58 \\
\hline Age range & $18-80$ & $19-86$ & $18-78$ & $24-74$ & $18-68$ & $24-56$ & $23-78$ & $26-74$ & $18-80$ & $24-69$ \\
\hline \# of females & 71 & 47 & 10 & 9 & 6 & 6 & 4 & 3 & 60 & 4 \\
\hline \# of males & 46 & 81 & 17 & 11 & 5 & 2 & 12 & 9 & 31 & 8 \\
\hline
\end{tabular}




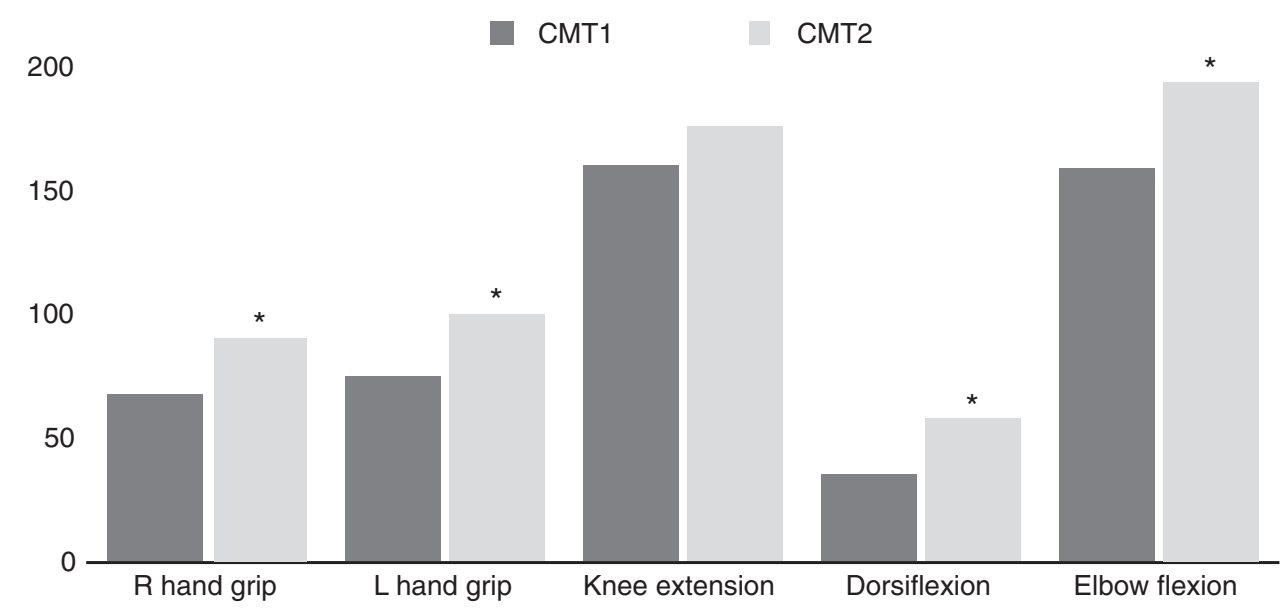

Figure 1: Comparison of CMT1 versus CMT2 participants. CMT1 participants were statistically significantly stronger than CMT2 participants in right-and left-hand grip, dorsiflexion, and elbow flexion $(p<0.05)$.

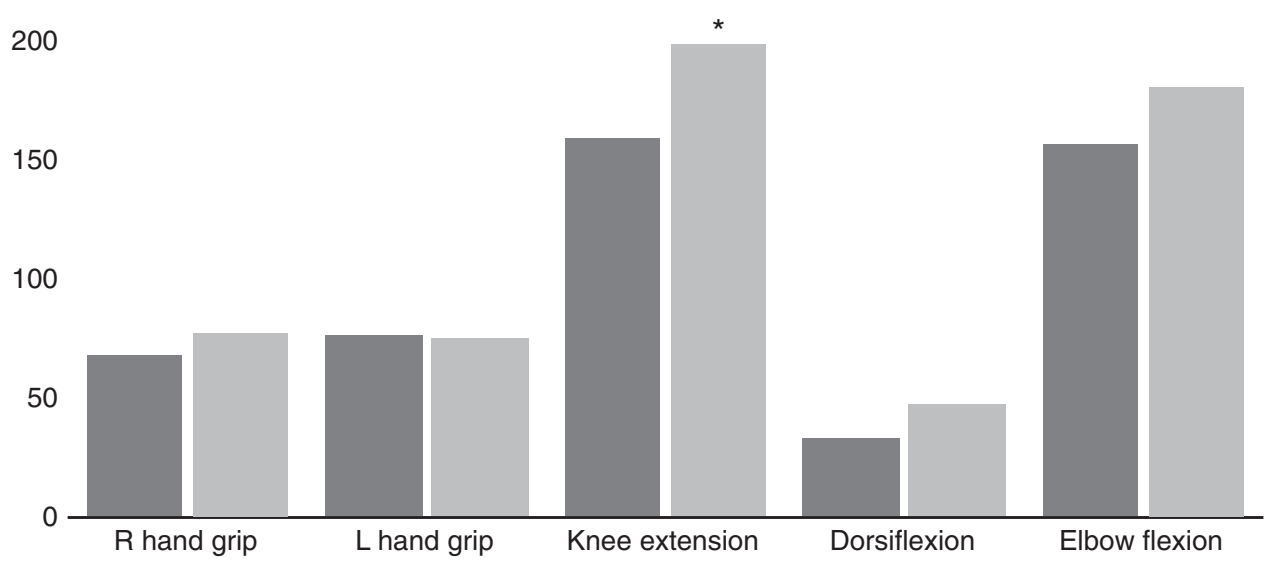

Figure 2: $C M T 1 B$ and $1 D$ participants were statistically significantly stronger than CMT1A participants in knee extension $(p<0.05)$.

those who did exercise had statistically stronger strength values in elbow flexion and dorsiflexion $(p<0.05)$ (Figure 5). Exercise did not have an impact on hand grip strength in either group (Table 2).

\section{Discussion}

Despite currently available treatment methods, individuals with CMT experience significant detriments to their quality of life. ${ }^{15,16}$ In particular, distal weakness results in foot

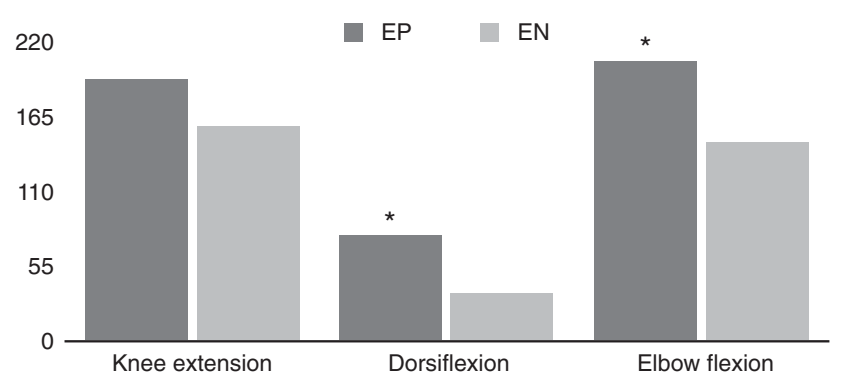

Figure 3: Comparison of EP versus EN groups. Those who did exercise were statistically significantly stronger than those who did not in dorsiflexion and elbow flexion $(p<0.05)$. deformities, gait difficulties, and imbalance. ${ }^{3,4}$ This provides an obvious target for therapy. However, the benefits of exercise in different CMT subtypes is an area of CMT management that continues to lack evidence.

In our study, we have shown that CMT patients who participate in self-directed whole-body exercise have greater strength values in ankle dorsiflexion and elbow flexion. This was true when all patients were compared, as well as when CMT1 and CMT2 were examined individually (excluding the CMT1 group, where only dorsiflexion remained statistically significant), decreasing the likelihood of CMT subtype imbalance confounding the results. These results are in keeping with the results of existing literature from randomized trials that exercise improves strength in CMT patients ${ }^{8,9}$ and should be included in management plans. We have also shown that exercise does not have an impact on hand grip strength, supporting previous evidence that exercise in CMT does not lead to overwork weakness. ${ }^{7}$ These results suggest that self-directed exercise may be a convenient, sustainable, and effective method of improving strength and decreasing disability in this population. The benefits on dorsiflexion are particularly notable, as distal weakness and the resulting foot deformities contribute heavily to many of the impairments these patients experience. 


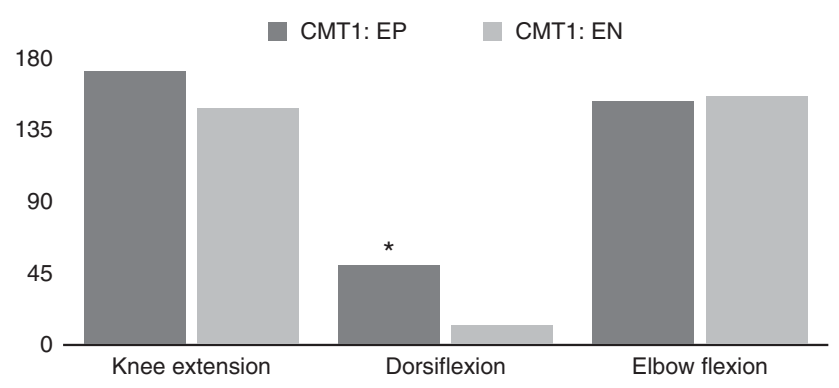

Figure 4: CMT1 participants in the EP group were statistically significantly stronger in dorsiflexion than those in the EN group $(p<0.05)$.

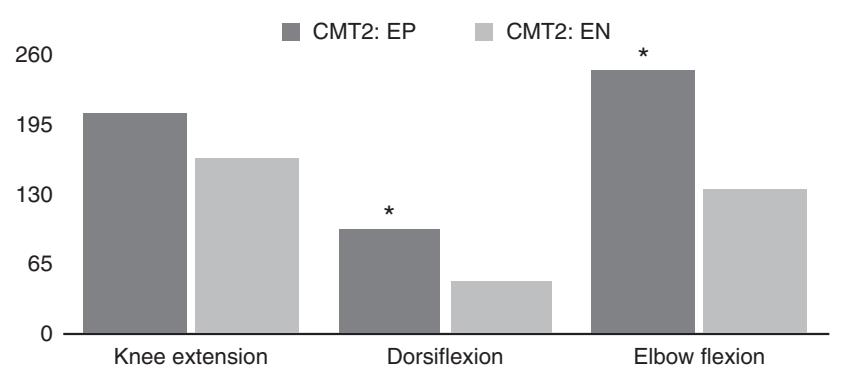

Figure 5: CMT2 participants who did exercise were statistically significantly stronger than those who did not in dorsiflexion and elbow flexion $(p<0.05)$.
When comparing strength of CMT1 versus CMT2 subtypes, CMT2 participants were stronger in right- and left-hand grip, ankle dorsiflexion, and elbow flexion. Of the CMT1 subtypes, CMT1A was statistically weaker than CMT1B and 1D in knee extension. Larger sample sizes would have allowed for more accurate comparison of these groups and may have led to more significant results in other muscle groups. Nonetheless, these results are in keeping with existing evidence that the combined axo-glial dysfunction (i.e., dysmyelination and secondary axonal atrophy) in CMT1 may lead to greater loss of strength compared to the strictly axonal degeneration in CMT2, ${ }^{17}$ and that this process may be more pronounced in CMT1A compared to other CMT1 subtypes. It is possible that the benefits gained from exercise may be particularly beneficial in this group; however, this cannot be determined based on our study design. Future studies should aim to more closely compare the effects of exercise on differing CMT subtypes and examine whether there is greater benefit for more severe phenotypes. Unfortunately, there were not enough participants with diagnoses of different CMT2 subtypes (e.g., 2K, 2F, 2I) in order to analyze these individually. Future studies should also be aimed at examining more of these participants in order to have a more conclusive dataset for all CMT subtypes.

Notwithstanding that a causal relation cannot be inferred from this retrospective chart review, the most notable limitation is the possibility that individuals with a milder CMT phenotype, and thus

Table 2: Summary of statistical analyses for all groups and strength values

\begin{tabular}{|c|c|c|c|c|c|c|c|c|c|c|c|}
\hline & & CMT1 & CMT2 & $\begin{array}{c}\text { Yes } \\
\text { Exercise }\end{array}$ & $\begin{array}{c}\text { No } \\
\text { Exercise }\end{array}$ & $\begin{array}{l}\text { Yes exercise: } \\
\text { CMT1 }\end{array}$ & $\begin{array}{l}\text { No exercise: } \\
\text { CMT1 }\end{array}$ & $\begin{array}{l}\text { Yes exercise: } \\
\text { CMT2 }\end{array}$ & $\begin{array}{l}\text { No Exercise: } \\
\text { CMT2 }\end{array}$ & CMT1A & $\begin{array}{c}\text { CMT1 } \\
\text { B/D }\end{array}$ \\
\hline \multirow{3}{*}{$\begin{array}{c}\mathbf{R} \text { hand grip } \\
(\mathbf{k g})\end{array}$} & $\mathbf{n}=$ & 117 & 125 & 26 & 19 & 11 & 8 & 15 & 11 & 91 & 12 \\
\hline & mean & 66.97 & $89.84 *$ & 71.464 & 78.962 & 57.486 & 62.725 & 81.716 & 90.771 & 66.795 & 76.788 \\
\hline & SD & 23.136 & 26.82 & 29.5233 & 26.630 & 14.647 & 13.387 & 33.721 & 28.049 & 22.593 & 30.518 \\
\hline \multirow{3}{*}{$\begin{array}{l}\mathbf{L} \text { hand grip } \\
(\mathrm{kg})\end{array}$} & $\mathbf{n}=$ & 117 & 125 & 26 & 19 & 11 & 8 & 15 & 11 & 91 & 12 \\
\hline & mean & 74.85 & 99.905* & 80.478 & 88.103 & 65.047 & 68.859 & 91.794 & 102.098 & 75.421 & 74.264 \\
\hline & SD & 27.723 & 32.94 & 35.797 & 33.085 & 17.028 & 20.476 & 41.9152 & 34.134 & 28.190 & 32.093 \\
\hline \multirow{3}{*}{$\begin{array}{c}\text { Knee ext } \\
(\mathbf{N m})\end{array}$} & $\mathbf{n}=$ & 116 & 116 & 24 & 18 & 10 & 8 & 14 & 10 & 90 & 12 \\
\hline & mean & 159.488 & 174.92 & 191.496 & 157.361 & 170.498 & 147.367 & 206.495 & 165.355 & 157.846 & 198.176* \\
\hline & SD & 63.929 & 87.2883 & 76.581 & 54.655 & 66.642 & 46.074 & 81.975 & 61.900 & 60.763 & 73.693 \\
\hline \multirow{3}{*}{$\begin{array}{c}\text { Dorsiflex } \\
(\mathbf{N m})\end{array}$} & $\mathrm{n}=$ & 116 & 127 & 26 & 20 & 11 & 8 & 15 & 12 & 90 & 12 \\
\hline & mean & 34.679 & 57.970* & 77.196* & 35.103 & $49.627 *$ & 12.355 & 97.413* & 50.269 & 32.505 & 46.577 \\
\hline & SD & 44.966 & 67.6458 & 63.468 & 36.261 & 38.727 & 24.479 & 71.3217 & 35.533 & 43.943 & 54.285 \\
\hline \multirow{3}{*}{$\begin{array}{c}\text { Elbow flex } \\
\text { (Nm) }\end{array}$} & $\mathbf{n}=$ & 109 & 110 & 23 & 14 & 10 & 7 & 13 & 7 & 87 & 11 \\
\hline & mean & 158.068 & 193.079* & $205.107 *$ & 145.240 & 152.954 & 154.629 & $245.225^{*}$ & 135.850 & 155.795 & 179.554 \\
\hline & SD & 62.489 & 87.5623 & 81.586 & 65.926 & 69.640 & 44.943 & 67.496 & 84.801 & 64.921 & 50.890 \\
\hline
\end{tabular}

$* \mathrm{p}<0.05$ 
a higher capacity to exercise, preselected themselves to exercise more than their counterparts with a more disabling phenotype. However, the presence of foot drop in participants in both the EP and EN groups suggests that the degree of disability may not have caused significant barriers to an ability to exercise. Given that this is a preliminary study, much work remains to be done to delineate the type of exercise prescription that would best address the needs of the CMT population. Additionally, understanding whether lifelong exercise has the potential to mitigate disease progression and ultimately change the natural history of their disease remains unknown and represents a significant limitation in the clinical management of individuals with CMT.

There are several other notable limitations to our study. A potential confound could include differences in the age and sex distribution of participants between the various groups. This limitation was addressed through adjustment of scores according to previously reported normative data. Importantly, conversion of strength scores did not alter the statistical findings, suggesting that the distribution of age and male-to-female ratios of participants were not significant. Further limitations of the study include the following: only a small number of patients met the inclusion criteria for exercise analysis; the study did not include longitudinal strength testing due to patient attrition; and, despite the use of inclusion and exclusion criteria for exercise, the study lacked a standardized measurement or definition of exercise. Despite these limitations, our study does provide preliminary evidence that (1) self-directed exercise regimes may be beneficial for CMT patients of varying subtypes, (2) that exercise is not detrimental for strength in these patients, and (3) that there is merit in exploring this area in future studies.

To our knowledge, ours is the first study to examine the association between self-directed exercise and strength in different CMT subtypes. Secondary measures were not examined in this study and should be a goal for subsequent research, including whether improvements in strength also result in benefits for gait and balance. At present, we have shown that even selfselected exercise may benefit CMT patients without causing overwork weakness. Given the known consequences of weakness on disability in this population, improving strength may have a dramatic impact on quality of life. The management plans of patients with CMT should be comprehensive and include accessible exercise programs.

\section{ACKNOWLEDGMENTS}

We would like to thank the patients, who continue to help inform research on CMT.

\section{DisCLOSURES}

Djurdja Djordjevic, Sabrina Fell, and Steven Baker hereby declare that have no conflicts of interest to disclose.

\section{REFERENCES}

1. Schenone A, Nobbio L, Monti Bragadin M, Ursino G, Grandis M. Inherited neuropathies. Curr Treat Options Neurol. 2011;13 (2):160-79.

2. Birouk N, Gouider R, Le Guern E, et al. Charcot-Marie-Tooth disease type $1 \mathrm{~A}$ with $17 \mathrm{p} 11.2$ duplication: clinical and electrophysiological phenotype study and factors influencing disease severity in 119 cases. Brain. 1997;120(Pt 5):813-23.

3. Burns J, Ryan MM, Ouvrier RA. Evolution of foot and ankle manifestations in children with CMT1A. Muscle Nerve. 2009; 39(2): 158-66.

4. Newman CJ, Walsh M, O'Sullivan R, et al. The characteristics of gait in Charcot-Marie-Tooth disease types I and II. Gait Posture. 2007;26(1):120-7.

5. Braathen GJ, Sand JC, Lobato A, Høyer H, Russell MB. Genetic epidemiology of Charcot-Marie-Tooth in the general population. Eur J Neurol. 2011;18(1):39-48.

6. Rose KJ, Raymond J, Refshauge K, North KN, Burns J. Serial night casting increases ankle dorsiflexion range in children and young adults with Charcot-Marie-Tooth disease: a randomised trial. Physiotherapy. 2010;56(2):113-9.

7. Piscosquito G, Reilly MM, Schenone A, et al. Is overwork weakness relevant in Charcot-Marie-Tooth disease? J Neurol Neurosurg Psychiatry. 2014;85(12):1354-8.

8. Kilmer DD. Response to resistive strengthening exercise training in humans with neuromuscular disease. Am J Phys Med Rehabil. 2002;81(Suppl 11):S121-6.

9. Sman AD, Hackett D, Fiatarone Singh M, Fornusek C, Menezes MP, Burns J. Systematic review of exercise for Charcot-Marie-Tooth disease. J Peripher Nerv Syst. 2015; 20(4):347-62.

10. Turna J, Baker S, Igdoura S. The effects of endurance and strength training on physical performance and quality-of-life of patients with Charcot-Marie-Tooth (CMT) disease [abstract]. In: 8th Annual Biology Undergraduate Symposium, presented by the Department of Biology, McMaster University, Hamilton, Ontario; 2012.

11. Beenakker EA, van der Hoeven JH, Fock JM, Maurits NM. Reference values of maximum isometric muscle force obtained in 270 children aged $4 \pm 16$ years by hand-held dynamometry. Neuromuscul Disord. 2001;11(5):441-6.

12. Harbo T, Brincks J, Andersen H. Maximal isokinetic and isometric muscle strength of major muscle groups related to age, body mass, height, and sex in 178 healthy subjects. Eur J Appl Physiol. 2012;112(1):267-75

13. Mathiowetz V, Kashman N, Volland G, Weber K, Dowe M, Rogers S. Grip and pinch strength: normative data for adults. Arch Phys Med Rehabil. 1985;66(2):69-74.

14. Mathiowetz V, Wiemer DM, Federman SM. Grip and pinch strength: norms for 6- to 19-year-olds. Am J Occup Ther. 1986;40 (10):705-11.

15. Vinci P, Serrao M, Millul A, et al. Quality of life in patients with Charcot-Marie-Tooth disease. Neurology. 2005;65(6): 922-924.

16. Pfeiffer G, Wicklein EM, Ratusinski T, Schmitt L, Kunze K. Disability and quality of life in Charcot-Marie-Tooth disease type 1. J Neurol Neurosurg Psychiatry. 2001;70(4):548-50.

17. Pareyson D, Scaioli V, Laurà M. Clinical and electrophysiological aspects of Charcot-Marie-Tooth disease. NeuroMolecular Med. 2006;8(1-2):3-22. 